\title{
PAGURUS BREVIDACTYLUS (STIMPSON) NOVO REGISTRO DE ANOMURA (DECAPODA, PAGURIDAE) PARA O LITORAL SANTA CATARINA, BRASIL
}

\author{
Paulo J. Rieger ${ }^{1}$ \\ Jackson L.B. Giraldi ${ }^{1,2}$
}

\begin{abstract}
Pagurus breVIDACTYlus (STIMPSON) NEW RECord of ANOMURA (DeCApoda, Paguridae) to the SEaboard of Santa Catarina, Brazil. Is registered for the first time in the South Brazilian coast, the ermit crab Pagurus brevidactylus Stimpson, 1859, wich previous South limit of distribution was at São Paulo State and now it is extended to the Santa Catarina State coast line. Were collected 100 ermit crabs, being 50 males and 50 females, from wich 20 ovigerous were found. The organisms were collected by scuba diving in Ponta da Sepultura and Retiro dos Padres beach, on the rock and sand bottom, at Bombinhas city, in October and November 1995.

KEY WORDS. Anomura, Paguridae, Pagurus brevidactylus, new record, Santa Catarina
\end{abstract}

De acordo com CoElHo \& RAmos (1987), na costa brasileira a família Paguridae está representada por oito gêneros que abrigam 19 espécies. No litoral brasileiro, o gênero Pagurus é representado por oito espécies, das quais quatro, Pagurus provenzanoi (Forest \& de Saint Laurent), Pagurus criniticornis (Dana), Pagurus exilis (Benedict) e Pagurus leptonyx (Forest \& de Saint Laurent) abrangem o litoral catarinense na sua distribuição geográfica, sendo que $P$. leptonyx tem em Santa Catarina o seu limite meridional de distribuição.

Com a presente nota, fica registrada para o litoral catarinense a presença de mais uma espécie do gênero Pagurus, com a espécie Pagurus brevidactylus (Stimpson), cuja distribuição anterior tinha como limite sul o estado de São Paulo, segundo COELHO \& RAMOS (1987), o qual encontra-se aqui ampliado para o estado de Santa Catarina.

Os exemplares de $P$. brevidactylus foram amostrados na região costeira do município de Bombinhas, nas praias de Retiro dos Padres e Sepultura, situadas no trecho do litoral compreendido entre as latitudes $27^{\circ} 06^{\prime} 00^{\prime \prime} \mathrm{S}$ (Ponta de Porto Belo) e $27^{\circ} 13^{\prime} 00^{\prime \prime S}$ (Ponta de Zimbros). As amostragens foram realizadas através de mergulhos autônomos efetuados junto à Ponta da Sepultura e ao Costão do Retiro dos Padres, dois acidentes pertencentes ao cordão rochoso que contorna a costa, interligando as praias de mesmo nome.

1) Laboratório de Crustacea Decapoda, Departamento de Ciências Morfo-biológicas, Fundação Universidade do Rio Grande. 96201-900 Rio Grande, Rio Grande do Sul, Brasil. E-mail: dmbpjr@super.furg.br

2) Bolsista de Iniciação Científica, FAPERGS/FURG. 
Tabela I. Pagurus brevidactylus, dados biométricos dos indivíduos coletados no município de Bombinhas, Santa Catarina, número amostral (n) de 50 machos e 50 fêmeas (20 ovigeras).

\begin{tabular}{lll}
\hline & Machos & Fêmeas \\
\hline LARGURA DA CARAPAÇA & & \\
Máximo & 3,33 & 3,33 \\
Mínimo & 1,62 & 1,71 \\
Média \pm desvio padrão & $2,57 \pm 0,34$ & $2,37 \pm 0,33$ \\
COMPRIMENTO DA CARAPAÇA & & \\
Máximo & 3,69 & 3,60 \\
Mínimo & 1,80 & 1,98 \\
Média & $2,95 \pm 0,38$ & $2,74 \pm 0,35$ \\
PESO & & \\
Máximo & 0,25 & 0,17 \\
Mínimo & 0,01 & 0,02 \\
Média \pm desvio padrão & $0,08 \pm 0,04$ & $0,05 \pm 0,03$ \\
\hline
\end{tabular}

Os animais foram capturados em outubro e novembro de 1995, em profundidades inferiores a oito metros, sobre fundo composto de superfícies rochosas, areia com cascalho biodetrítico e agrupamentos isolados de rochas, em condições climáticas favoráveis, com vento NE (nordeste) de fraco a moderado, mar calmo, dias de pouca e nenhuma nebulosidade e visibilidade variando de dois a cinco metros.

Das amostras triadas foram analisados 100 indivíduos, sendo 50 machos e 50 fêmeas, encontrando-se 20 fêmeas ovígeras, cujos dados constam da tabela I .

O material analisado está depositado na coleção científica do Laboratório de Zoologia de Crustacea Decapoda do Departamento de Ciências Morfobiológicas, Universidade Federal de Rio Grande, Rio Grande, Rio Grande do Sul, lote de número 551 .

AGRADECIMENTO. Os autores agradecem à FAPERGS pelo apoio ao desenvolvimento de nossas atividades científicas através do processo número 93.0032.4.

\section{REFERÊNCIA BIBLIOGRÁFICA}

Coelho, P.A. \& M. Ramos-PorTo. 1987. Sinopse dos crustáceos decápodos brasileiros (famílias Callianassidae, Callianideidae, Upogebiidae, Parapaguridae, Diogenidae). Trab. Oceanográfico, Recife, 19: 27-53.

Recebido em 25.VII.1996; aceito em 28.V.1997. 